\title{
PRINCÍPIOS CONSTITUCIONAIS DO ORDENAMENTO DO TERRITÓRIO
}

\author{
Fernanda do Carmo
}

Doutoranda em Políticas Públicas, Instituto Universitário de Lisboa (ISCTE-IUL), Lisboa, Portugal

Resumo O presente artigo tem como objetivo analisar o posicionamento do ordenamento do território na Constituição da República Portuguesa, considerando os princípios e fundamentos constitucionais e os desenvolvimentos introduzidos pelos processos de revisão. Com este objetivo analisa-se a inscrição do ordenamento do território como tarefa fundamental do estado, bem como a sua associação aos direitos à habitação e urbanismo e ao ambiente e qualidade de vida, à promoção do desenvolvimento económico e social e da coesão territorial e à concretização dos princípios da subsidiariedade, autonomia, descentralização e participação, apresentando-se uma leitura de contexto das alterações verificadas. Conclui-se que o estatuto constitucional do ordenamento do território é amplo, demonstrando uma importância social que não é reconhecida na sua aplicação prática.

Palavras-chave: Constituição da República Portuguesa, ordenamento do território, habitação e urbanismo, ambiente e qualidade de vida, desenvolvimento económico e social, região-planeamento.

Abstract This article aims to analyse the position of spatial planning in the Constitution of the Portuguese Republic (CRP), while considering the various constitutional principles and bases and the developments introduced by the periodic revisions since the original text in 1976. The authors look at how the CRP makes spatial planning one of the state's fundamental tasks, and at how it is linked to the rights to housing and urbanism, the environment and quality of life, the promotion of economic and social development, territorial cohesion and the implementation of the principles of subsidiarity, autonomy, decentralisation and participation, presenting a contextual reading of the changes over the years. They conclude that the constitutional status of spatial planning is broad, demonstrating a theoretical / conceptual social importance that is not fully reflected in its practical application.

Keywords: Portuguese Constitution, spatial planning, housing and urbanism, environment and quality of life, economic and social development, planning region.

Résumé Cet article analyse la place de l'aménagement du territoire dans la Constitution portugaise, en considérant les principes et fondements constitutionnels et les évolutions introduites par les processus de révision. Il analyse l'aménagement du territoire en tant que devoir fondamental de l'Etat et son association aux droits au logement et à l'urbanisme ainsi qu'à l'environnement et à la qualité de vie, à la promotion du développement économique et social et de la cohésion territoriale et à la mise en œuvre des principes de subsidiarité, d'autonomie, de décentralisation et de participation, en présentant une lecture de contexte des changements observés. L'article conclut que le statut constitutionnel de l'aménagement du territoire est vaste, ce qui démontre une importance sociale qui n'est pas reconnue dans son application pratique.

Mots-clés: Constitution portugaise, aménagement du territoire, logement et urbanisme, environnement et qualité de vie, développement économique et social, région-planification.

Resumen Este artículo tiene como objetivo analizar la posición de la ordenación del territorio en la Constitución Portuguesa, considerando los principios y los fundamentos constitucionales y desarrollos introducidos por el proceso de revisión. Con este objetivo se analiza la ordenación del territorio como una tarea fundamental del Estado, así como su asociación con los derechos a la vivienda y urbanismo y el medio ambiente y calidad de vida, la promoción del desarrollo económico y social y la cohesión territorial y la aplicación de los principios de subsidiariedad, la autonomía, la descentralización y la participación, presentando una lectura contexto de los cambios observados. Llegamos a la conclusión de que la situación constitucional de la ordenación del territorio es amplia, lo que demuestra una importancia social que no se reconoce en su aplicación práctica.

Palabras-clave: Constitución Portuguesa, ordenación del territorio, vivienda y urbanismo, medio ambiente y calidad de vida, desarrollo económico y social, región de planificación. 
A Constituição da República Portuguesa (CRP) consagra o ordenamento do território como um fim a prosseguir pelo estado ${ }^{1}$ no quadro dos princípios constitucionais fundamentais.

O ordenamento do território é uma política pública transversal que integra objetivos de organização territorial e desenvolvimento socioeconómico e tem repercussão em múltiplas áreas da vida social e económica. A importância e a transversalidade desta política pública ficaram implícitas no texto constitucional originário, de 1976, e foram depois evidenciadas nas revisões constitucionais de 1982,1989 e 1997, estando hoje consagrado "assegurar um correto ordenamento do território" como uma das tarefas fundamentais do estado, nos termos do artigo 9.ㅇ, alínea $e$, da CRP.

A tarefa de assegurar um correto ordenamento do território assume, por sua vez, dimensões fundamentais para a concretização de princípios e objetivos expressos em três grandes domínios constitucionais, o dos direitos e deveres sociais, o da organização económica e o da organização do poder político.

Numa primeira dimensão, o ordenamento do território encontra-se expressamente inscrito nos direitos e deveres fundamentais como uma incumbência atribuída ao estado, partilhada com as regiões autónomas e as autarquias locais, no sentido de assegurar a efetivação de direitos e deveres sociais, designadamente $o$ direito à habitação e urbanismo (artigo 65.․) e o direito ao ambiente e qualidade de vida (artigo 66. $\left.{ }^{\circ}\right)$.

Todavia, enquanto objetivo e tarefa do Estado, o ordenamento do território não se esgota no estipulado nos artigos $65 .^{\circ}$ e 66 . $^{\circ}$. Na parte da organização económica e no quadro dos objetivos da promoção do desenvolvimento económico e social encontramos importantes referências constitucionais que apelam ao ordenamento do território, enquanto base e instrumento privilegiado do desenvolvimento territorial. Esta ligação é salientada por Miranda e Medeiros (2006: 192) e por Garcia (2010: 27) que frisam a relação entre a tarefa de efetivação dos direitos sociais referidos (artigo 9.․ㅡ, alínea $e$ ) e a promoção do desenvolvimento económico e social.

Assim, numa segunda dimensão, no quadro da organização económica, a tarefa de assegurar um correto ordenamento do território assume uma importância evidente: quer para a aplicação do princípio do planeamento democrático do desenvolvimento económico e social (artigo 80.ํ); quer para a realização de incumbências materiais, como as que visam a promoção do bem-estar e da qualidade de vida, no quadro de uma estratégia de desenvolvimento sustentável, e a promoção

1 Segundo Miranda e Medeiros (2006: 185), o texto constitucional apresenta uma sequência programática de crescente densificação, devendo entender-se as tarefas como fins ou grandes metas a atingir pelo estado, e as incumbências como especificações de tarefas ao serviço de direitos e interesses a salvaguardar ou a promover. Salientam que "a referência ao Estado significa, aqui, o Estado - poder central, manifestado, primeiro, através dos órgãos de soberania e, depois, através de outros órgãos e até de pessoas coletivas em que, por razões funcionais, se desdobra. Já relativamente a muitas das incumbências que ao Estado são atribuídas no domínio dos direitos económicos, sociais, culturais e ambientais o termo Estado abrange também as regiões autónomas e, por vezes, as autarquias locais." 
da coesão, orientando o desenvolvimento e eliminando diferenças económicas, sociais e territoriais; quer para a realização de incumbências operacionais, como as que visam a criação de instrumentos de planeamento e a integração de preocupações de racionalidade e sustentabilidade na utilização dos recursos naturais, no âmbito de políticas setoriais de interesse económico e, também, dos objetivos da

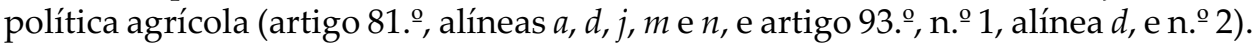
Ainda em matéria de organização económica sublinhamos a ligação entre o ordenamento do território e os planos de desenvolvimento económico, no campo dos objetivos e dos processos (artigos $90^{\circ}$ e $91^{\circ}$ ).

Numa terceira dimensão, ao nível dos princípios fundamentais e da organização do poder político, o ordenamento do território, por via do sistema de planeamento territorial e dos respetivos programas e planos, assume um papel instrumental relevante para a operacionalização dos princípios da subsidiariedade, da autonomia regional e das autarquias locais e da descentralização democrática da administração pública (artigo $6 .$. , n.. 1), bem como para a tarefa fundamental de assegurar e incentivar a participação democrática dos cidadãos na resolução dos problemas nacionais (artigo 9.․, alínea $e$ ).

À luz dos princípios constitucionais, o sistema de planeamento consagrado na ordem jurídica portuguesa desde 1998, pela Lei de Bases da Política de Ordenamento do Território e de Urbanismo (LBPOTU), ${ }^{2}$ estabelece mecanismos e formas de interlocução de entidades e de conciliação dos interesses públicos nacionais e locais, prosseguidos pela administração central, regional e local, definindo um quadro legal que aponta para o exercício de competências partilhadas em matéria de ordenamento e desenvolvimento do território, em concretização dos princípios da organização do poder local e da descentralização administrativa (artigos 235..$^{\circ}$ e 237..$^{\circ}$ ).

Considera-se, pois, que é na triangulação de três domínios constitucionais - o domínio dos direitos à habitação e urbanismo e ao ambiente e qualidade de vida, enquanto direitos sociais positivos e de última geração; o domínio da organização económica, em matéria de desenvolvimento económico e social; e o domínio da organização do poder político, no que diz respeito à concretização dos princípios da subsidiariedade, autonomia, descentralização e participação, através do sistema de planeamento e gestão territorial - que o ordenamento do território se posiciona na CRP.

\section{O ordenamento do território como tarefa fundamental do estado}

A lista inicial das tarefas fundamentais do estado, como tal autonomamente identificadas no texto constitucional de 1976, restringiu-se ao enunciar de opções constitucionais básicas em matéria de independência, democracia e socialização, tendo sido depois revista e aumentada.

2 A Lei n. ${ }^{\circ}$ 48/1998, de 11 de agosto aprovou a primeira Lei de Bases da Política de Ordenamento do Território e de Urbanismo perspetivando a existência de regiões administrativas mas estabelecendo mecanismos supletivos de exercício de competências até à sua criação. Esta Lei foi revista pela Lei n.. $31 / 2014$, de 30 de maio 
O ordenamento do território foi expressamente identificado na CRP como um fim e tarefa fundamental em 1989, através da introdução da incumbência de o estado "assegurar um correto ordenamento do território" (artigo 9.o, alínea e).

A inscrição do ordenamento do território nas tarefas do estado constituiu um corolário dos direitos e deveres sociais relativos à habitação e urbanismo e ao ambiente e qualidade de vida e reforçou as suas incumbências de efetivação destes direitos e de promoção do desenvolvimento socioeconómico, consagradas na CRP desde 1976. Com a revisão de 1989, o estado, ficou explicitamente comprometido com a realização do fim constitucional de assegurar "um correto ordenamento do território", na margem de conformação que lhe é dada pelo termo "correto".

Esta inscrição veio fortalecer a posição do ordenamento do território no quadro constitucional geral e reforçar as obrigações do estado neste domínio, impelindo-o à prossecução ativa de ações de definição e aplicação de um correto ordenamento do território, quer enquanto fim a atingir, quer enquanto atividade específica a desenvolver, ao serviço da efetivação de direitos económicos, sociais, culturais e ambientais e do cumprimento dos objetivos de coesão económica, social e territorial. Miranda e Medeiros (2006: 191) referem, precisamente, que os direitos económicos, sociais, culturais e ambientais "dependem, em larga medida, na sua concretização, de condições de facto a obter e a construir".

Em termos de percurso evolutivo, salienta-se que logo na primeira revisão constitucional de 1982 foram incluídas nas tarefas fundamentais do Estado dimensões intrinsecamente ligadas ao ordenamento do território, como a defesa da natureza e do ambiente, a preservação dos recursos naturais e a proteção e valorização do património cultural, sendo a este grupo que, em 1989, foi acrescida a tarefa de "assegurar um correto ordenamento do território".

Este desenvolvimento reflete a influência do contexto externo após adesão de Portugal à Comunidade Económica Europeia, nomeadamente os desafios da política regional europeia e a influência dos referenciais concetuais europeus em matéria ordenamento do território, ${ }^{3} \mathrm{e}$ traduz o contexto interno associado à reforma da organização da administração periférica do estado, encetada após $1986,{ }^{4}$ que veio reforçar, no âmbito regional, as regiões-planeamento e a ligação entre o ordenamento do território, o ambiente e o desenvolvimento regional.

Posteriormente, em 1997, foi não só enfatizada a tarefa de efetivar os direitos ambientais, com a nomeação destes a par dos direitos económicos, sociais e culturais, no

3 Embora o ordenamento do território não configure uma política comum, existe um historial de construção de referenciais europeus partilhados, no âmbito de reuniões informais dos ministros responsáveis pelo ordenamento do território, cujo expoente foi, uma década mais tarde, o documento European Spatial Development Perspective.

4 Em 1986, sob a égide do ministro Valente de Oliveira, reformou-se o aparelho do estado com a criação do Ministério do Plano e da Administração do Território, responsável pelo planeamento regional e pela coordenação de políticas numa perspetiva global (incluindo a matéria económica), pela administração local, pelo ordenamento do território e pelos recursos naturais e ambiente. As Comissões de Coordenação Regional foram integradas no MPAT, na qualidade de órgãos da administração periférica do estado, sendo-lhes atribuída a execução e promoção destas áreas de política e a participação na programação e gestão dos fundos comunitários. 
âmbito da tarefa de promoção do bem-estar e da qualidade de vida, como foi também inscrita como nova tarefa "a promoção do desenvolvimento harmonioso de todo o território nacional (artigo 9.․ㅡ alínea g). Esta revisão ocorreu num período de preparação da LBPOTU, publicada em 1998, e de preparação da lei de criação das regiões administrativas, referendada nesse mesmo ano.

O estado ficou, assim, vinculado a praticar os atos e tomar as providências necessárias para alcançar os fins constitucionais do ordenamento do território e a criar as condições necessárias para a promoção da efetivação dos direitos sociais e dos objetivos de desenvolvimento territorial harmonioso e equilibrado, nomeadamente através do planeamento urbanístico e biofísico, mais ligado aos regimes de ocupação e uso do solo, e do planeamento estratégico, mais ligado às opções de desenvolvimento económico e social territorial.

Concomitantemente o estado viu reforçada a sua incumbência de promover os quadros legais, os instrumentos e as vias organizativas para atingir estes fins, seguindo modelos de coordenação e partilha da sua ação com as regiões autónomas e as autarquias locais e de promoção da iniciativa, envolvimento e participação dos cidadãos e grupos sociais na resolução dos problemas nacionais., havendo forte expetativa na criação das regiões.

Posteriormente ao referendo e na impossibilidade de prosseguir a instituição das regiões administrativas, as atividades de planeamento e gestão de âmbito regional mantiveram-se nas regiões-planeamento e na esfera de competências das Comissões de Coordenação Regional (atuais CCDR), por via da desconcentração administrativa.

$\mathrm{Na} \mathrm{CRP}$ o conceito de ordenamento do território consolidou-se em torno dos conceitos de urbanismo, ambiente e desenvolvimento regional, refletindo as filiações do planeamento territorial português: o planeamento urbanístico, o planeamento regional e o planeamento biofísico (Ferrão, 2010: 62-70; Campos e Ferrão, 2015: 7-31), mostrando capacidade de adaptação à influência europeia, nomeadamente no que se refere aos princípios da subsidiariedade e da coesão económica, social e territorial.

É, assim, na conjugação de várias alíneas do artigo 9. ㅇ da CRP que deve ser entendida a tarefa do estado no domínio do ordenamento do território, designadamente as alíneas: $e$, que estabelece o assegurar de um correto ordenamento do território; $d$, que refere a promoção do bem-estar e qualidade de vida e da efetivação dos direitos económicos, sociais, culturais e ambientais; $g$, relativa à promoção do desenvolvimento territorial harmonioso; bem como da alínea $c$, que estabelece a necessidade de assegurar e incentivar a participação democrática dos cidadãos na resolução dos problemas nacionais.

\section{O ordenamento do território associado aos direitos à habitação e urbanismo e ao ambiente e qualidade de vida}

A parte I da CRP estabelece e desenvolve os direitos e deveres fundamentais das pessoas nas relações entre si e com o estado, detendo um forte poder conformador 
da ordem jurídica infraconstitucional e dando um importante contributo, em conjunto com a parte relativa à organização económica, para a definição do "tipo constitucional de sociedade", como salientam Canotilho e Moreira (2007: 294).

Sendo uma tarefa fundamental do estado, o ordenamento do território não é definido como um direito em si mesmo, delimitado em artigo autónomo, antes surge, neste capítulo, como um dever e um direito transversal, concebido como uma obrigação programática de política pública que prossegue a racional organização do território e o desenvolvimento socioeconómico harmonioso e sustentável e que proporciona condições para a efetivação de direitos positivos de natureza social, como é o caso do direito à habitação e urbanismo (artigo 65.. $)$ e dos direitos e deveres de última geração, como é o caso do direito ao ambiente e qualidade de vida (artigo 66. ${ }^{\circ}$ ), bem como para atingir objetivos de desenvolvimento económico e social, como veremos no ponto seguinte.

No caso do direito à habitação desde 1976 que a CRP estabelece que, para que este seja efetivado, incumbe ao estado "programar e executar uma política de habitação inserida em planos de reordenamento geral do território e apoiada em planos de urbanização que garantam a existência de uma rede adequada de transportes e de equipamento social" (artigo 65.⿳, alínea a). Resulta desta formulação uma incumbência de promover o ordenamento do território com base em planos de reordenamento geral (com a expressão "reordenamento" a frisar a necessidade de transformar uma realidade existente, de conotação negativa), a desenvolver a montante da elaboração dos planos urbanísticos reguladores da produção de solo urbano e da urbanização e edificação.

Também no caso do direito ao ambiente e qualidade de vida o texto constitucional de 1976 atribui ao estado uma incumbência de ordenamento do território: "ordenar o espaço territorial de forma a construir paisagens biologicamente equilibradas" (artigo 66.. , n.․ำ 2, alínea $b$ ). Neste caso a incumbência de ordenar o território assenta numa preocupação geral de génese biofísica e paisagística que não se esgota nem confunde com outras dimensões mais estritas ou setoriais da concretização deste direito, designadamente a poluição, a criação de parques e reservas e a classificação e proteção de paisagens e sítios, de forma a garantir a conservação da natureza e a preservação de valores culturais e o aproveitamento racional dos recursos, salvaguardando a sua renovação e estabilidade ecológica.

A leitura da Constituição permite-nos equacionar duas visões para o posicionamento do ordenamento do território no quadro dos direitos sociais fundamentais: uma visão do ordenamento do território como subsidiário do direito à habitação e do direito ao ambiente e qualidade de vida e via instrumental para a concretização destes dois direitos, ou uma visão do ordenamento do território menos redutora, que o posiciona como uma política pública transversal e estruturante da organização territorial e do desenvolvimento socioeconómico e, nesses termos, crucial para a boa concretização de direitos e deveres sociais fundamentais e para o planeamento do desenvolvimento económico e social num quadro de harmonia e equilíbrio territorial, sustentabilidade e bem-estar social.

Defendemos esta última visão, que julgamos contextualizada à época da elaboração da CRP e reconhecida na alteração constitucional de 1989, com a 
inscrição da tarefa fundamental do estado de "assegurar o correto ordenamento do território".

Esta solução constitucional que considera o ordenamento do território como uma tarefa fundamental do estado a prosseguir em vários domínios constitucionais, com o recurso ao planeamento, oferece-se contextualizada nas tradições e filiações do ordenamento do território em Portugal, o planeamento urbanístico, o planeamento biofísico e o planeamento regional, e nos ideais das comunidades profissionais e atores políticos que ao longo do tempo participaram e influenciaram a redação da CRP, na sua origem e nas posteriores revisões. ${ }^{5}$

Em reforço desta leitura salientamos que apesar da importância e premência que a produção de habitação assumia em 1976, quando existiam gravíssimos problemas de construção precária e insalubre, fenómenos de edificação ilegal e necessidades acrescidas pelo retorno das ex-colónias, o texto originário da CRP não se limitou a fomentar a produção de solo urbano por via de planos de urbanização, antes reforçou a necessidade de enquadrar o planeamento urbanístico e a identificação de solo urbano em visões de ordenamento geral do território.

E salientamos, também, que no âmbito do ambiente e qualidade de vida a inscrição no texto originário da incumbência de "ordenar o espaço territorial de forma a construir paisagens biologicamente equilibradas" deu, desde logo, expressão à noção de organização territorial e de equilíbrio, racionalização e sustentabilidade do desenvolvimento, em alinhamento com preocupações internacionais patentes na Conferência de Estocolmo de 1972.

A formulação constitucional reconheceu ao ordenamento do território um papel transversal e fundamental para a concretização do direito ao ambiente e este deu à política de ambiente uma visão ampla e inovadora, numa perspetiva biofísica e socioeconómica. Fadigas (2015: 133) refere que a valorização da paisagem no âmbito do ordenamento do território representou uma inovação concetual e que a introdução das questões ambientais no processo de ordenamento territorial foi um dos aspetos mais marcantes das políticas públicas naquele período e no que se lhe seguiu.

Também Canotilho e Moreira (2007: 322 e 845) e Miranda e Medeiros (2006: 1341) salientam o peso do direito ao ambiente no texto constitucional, frisando o caráter pioneiro e a abordagem inovadora da associação entre ambiente e qualidade de vida que, numa compreensão antropocêntrica do ambiente, levam a consagrá-lo como direito fundamental. Segundo Canotilho e Moreira (2007: 855), a Constituição aponta para uma visão de ambiente que considera sistemas ecológicos, físicos, biológicos e fatores económicos, sociais e culturais, encerrando uma compreensão estrutural-funcional de ambiente em que os sistemas e os fatores são interativos entre si e produzem efeitos direta ou indiretamente sobre a qualidade de vida.

5 Salienta-se, em 1976, o papel de Gonçalo Ribeiro Teles enquanto subsecretário de estado do Ambiente em conjunto com o secretário de estado da Habitação e Urbanismo, Nuno Portas, no I Governo Provisório e, no início dos anos 80, como Ministro da Qualidade de Vida, na projeção das políticas de ambiente e na ascensão do planeamento biofísico. 
Não obstante, não podemos deixar de evidenciar que no texto constitucional de 1976 a formulação do ordenamento do território e dos seus instrumentos de planeamento apresentava uma conotação predominantemente urbanística e biofísica, uma vez que, no domínio do desenvolvimento económico e social a Constituição consagrava um quadro de planeamento específico, com órgãos próprios, destinado a orientar, coordenar e disciplinar o desenvolvimento no sentido da transformação da economia e da sociedade e, como tal, acima dos demais instrumentos de planeamento, configuração que foi eliminada com as posteriores revisões constitucionais e com a evolução do conceito de "Plano" para "planos de desenvolvimento económico e social".

As alterações constitucionais nestes dois artigos ocorreram nas revisões de 1982, 1989 e 1997, registando-se uma evolução da consagração dos direitos à habitação e ao ambiente e qualidade de vida que não afetou a visão inicial do ordenamento do território, antes pelo contrário, reforçou-a.

No caso do direito à habitação as alterações iniciaram-se na revisão de 1989, com a retirada das menções à socialização do solo urbano, através da sua nacionalização e municipalização, a favor do recurso a instrumentos de expropriação dos solos urbanos necessários à urbanização, mantendo-se nesta fase e até 1997, a atribuição de o estado e das autarquias locais exercerem o efetivo controlo do parque imobiliário.

Em 1997 ocorreu uma revisão mais profunda do direito à habitação e da definição do papel do estado. Em primeiro lugar a epígrafe do artigo 65.. foi alterada, passando de "Habitação" para a "Habitação e urbanismo", dando ao enunciar deste direito uma conotação mais vasta e consentânea com as preocupações de política urbana e acolhendo melhor o reforço do planeamento urbanístico, nos termos das alterações inscritas no corpo do artigo. Para Fadigas (2015: 153), “a autonomização do urbanismo como aspeto particular do ordenamento do território e seu instrumento representou, a partir daqui, um novo paradigma quanto ao modo de encarar as realidades territoriais. Reconhecendo a especificidade das questões urbanas no quadro da organização territorial ..."

A revisão de 1997 introduziu um quadro explícito de obrigações partilhadas entre o estado, as regiões autónomas e as autarquias locais, quer na construção de habitação social e económica, assumindo-se neste campo um papel de prestador, quer na regulamentação e disponibilização do solo urbano para os demais fins habitacionais e outros, assente no planeamento urbanístico e na expropriação de solos para fins de utilidade pública urbanística, assumindo-se aqui, essencialmente, um papel de regulador.

Assim, a partir 1997 ao estado incumbe: "Promover, em colaboração com as autarquias locais, a construção de habitações económicas e sociais" (artigo 65.⿳, n. - 2, alínea $b$ ). E nos demais âmbitos: "O estado, as regiões autónomas e as autarquias locais definem as regras de ocupação, uso e transformação dos solos urbanos, designadamente através de instrumentos de planeamento, no quadro das leis respeitantes ao ordenamento do território e ao urbanismo e procedem às expropriações dos solos que se revelem necessárias à satisfação de fins de utilidade pública urbanística" (artigo 65. ․ n.. 4 ), sendo garantida "a participação dos interessados na 
elaboração dos instrumentos de planeamento urbanístico e de quaisquer outros de planeamento físico do território" (artigo 65. ․, n.. 5).

Manteve-se, no entanto, o posicionamento do ordenamento do território como política pública de fundo, tendo sido nesta revisão que se atualizou a expressão "planos de reordenamento geral do território" para "planos de ordenamento geral do território", adequando o texto constitucional à ordem jurídica infraconstitucional vigente e à prática do sistema de planeamento.

Em suma, em 1997 a Constituição consagrou o urbanismo como um direito e os planos urbanísticos como os principais definidores do aproveitamento urbanístico do solo e da dimensão social da propriedade privada, numa perspetiva mais vasta do que a da habitação, ${ }^{6}$ e reafirmou o ordenamento do território como uma política pública abrangente, assente sobretudo num sistema de planeamento e num quadro de competências partilhadas entre o estado, as regiões autónomas e as autarquias locais.

Saliente-se que a Constituição deixou em aberto a definição em concreto das competências de cada nível de poder, remetendo para as leis respeitantes ao ordenamento do território e ao urbanismo essa definição, com a garantia de estas serem matérias da reserva relativa de competência legislativa da Assembleia da República. Canotilho e Moreira (2007: 838) referem precisamente que a Constituição impõe ao estado, às regiões autónomas e às autarquias locais, de acordo com a respetiva esfera de competências no governo do território, a definição da ocupação, uso e transformação dos solos.

Decorre, pois, da CRP um certo grau de liberdade para que o quadro legal do ordenamento do território e urbanismo delimite a esfera de competências e o âmbito de atuação de cada nível de poder, naturalmente no quadro de reserva de competências, de acordo com os princípios constitucionais fundamentais e a organização do poder político e tendo por respeito o quadro infraconstitucional que destes decorre.

Esta definição ocorreu logo em 1998 com a aprovação da LBPOTU, que desenhou as competências de cada nível no âmbito da arquitetura do sistema de planeamento, bem como as formas de interlocução de entidades e os mecanismos de interação coordenada dos planos. ${ }^{7}$ Neste sistema os planos territoriais, que estabelecem os regimes de uso do solo e vinculam diretamente os particulares, competem às autarquias locais, enquanto ao estado, em partilha com as regiões autónomas, competem os instrumentos de desenvolvimento territorial, na qualidade de instrumentos estratégicos, programáticos e orientadores que definem o quadro de referência do ordenamento do território. ${ }^{8}$ Isto sem prejuízo de o estado

6 Note-se que as expropriações deixam de ser associadas ao controlo do parque imobiliário, passando a estar associadas à utilidade pública de execução dos planos urbanísticos.

7 A elaboração da Lei de Bases de 1998, promovida pelo ministro João Cravinho, constituiu um marco fundamental na afirmação da política de ordenamento do território como política pública autónoma e na construção de um sistema de gestão territorial e de coordenação das políticas de base territorial, no espírito da CRP.

8 Na recente revisão da Lei de Bases (Lei n. ㅇ 31/2014, de 30 de maio) a distinção entre "instrumentos de planeamento territorial" e "instrumentos de desenvolvimento territorial" passou a ser efetuada através da terminologia "planos territoriais" e "programas territoriais". 
poder estabelecer regimes de tutela de interesses públicos e de salvaguarda de recursos e valores de relevância nacional.

Quanto à evolução do direito ao ambiente e qualidade de vida verifica-se que este é um dos casos de ampliação significativa de conteúdos ao longo das sucessivas revisões constitucionais, acompanhando o afirmar da política de ambiente e a necessidade de incrementar a consideração das preocupações ambientais nas demais políticas públicas.

Em 1976 as incumbências do estado incluíram a de "ordenar o espaço territorial de forma a construir paisagens biologicamente equilibradas" (artigo 66.. , n.. 2 , alínea $b$ ), a par com as de prevenir e controlar a poluição e a erosão, de criar e desenvolver reservas e parques naturais e classificar paisagens e sítios, de modo a garantir a conservação da natureza e a preservação de valores culturais, e de promover o aproveitamento racional dos recursos naturais, salvaguardando a sua capacidade de renovação e estabilidade ecológica.

Em 1989 e 1997 esta incumbência geral de ordenamento foi aprofundada. Na primeira data, o "ordenar o espaço territorial" deu lugar a "ordenar e promover o ordenamento do território, tendo em vista a correta localização das atividades, um equilibrado desenvolvimento socioeconómico" e, na segunda, o objetivo final de alcançar "paisagens biologicamente equilibradas" deu lugar ao de "valorização da paisagem".

Por via do direito ao ambiente e qualidade de vida o dever de ordenamento do território assumiu em 1989 uma formulação moderna no quadro da formulação do artigo $66 . \stackrel{\circ}{\circ}$ n.. 2 , alínea $b$, que juntou ordenamento do território, ambiente e desenvolvimento regional, como referem Miranda e Medeiros (2006: 1351), e apontou para a necessidade de integração e coordenação de atividades setoriais, em total alinhamento com os princípios e objetivos da Carta Europeia do Ordenamento do Território, aprovada em 1984, onde o ordenamento do território foi definido como “... uma política que se desenvolve numa perspetiva interdisciplinar e integrada, tendente ao desenvolvimento equilibrado das regiões e à organização física do espaço segundo uma estratégia de conjunto" (DGOT, 1988: 9).

Depois desta atualização do conceito de ordenamento do território, realizada em 1989, em 1997 foram introduzidas no âmbito do direito ao ambiente e qualidade de vida outras dimensões contribuintes de uma visão atual do ordenamento do território, designadamente o aditamento introdutório, que frisa que o direito ao ambiente é assegurado no quadro de um "desenvolvimento sustentável" (artigo 66. ․ , n.ำ 2), e a inscrição do "respeito pelo princípio da solidariedade entre gerações" na promoção do aproveitamento racional dos recursos (artigo 66. ․ n.. o 2, alínea $d$ ).

Em 1997 são ainda acrescidas novas incumbências importantes, relacionadas com a qualidade ambiental urbana, a concretizar em colaboração com as autarquias locais, com a integração de objetivos ambientais nas políticas de âmbito setorial, com a promoção da educação ambiental e com o assegurar de uma política fiscal que compatibilize desenvolvimento com proteção do ambiente e qualidade de vida acrescida, e ainda a obrigação do estado de assegurar o direito ao ambiente "com o envolvimento e a participação dos cidadãos" (artigo 66.. , n.․ำ). 
A revisão de 1997 reforçou a amplitude da política de ambiente em associação com o ordenamento do território, em particular através do desenvolvimento da noção de desenvolvimento sustentável e de solidariedade entre gerações e de integração das preocupações ambientais em todas as políticas, denotando a influência do Relatório da Comissão Mundial sobre Meio Ambiente e Desenvolvimento, de 1987, e da Conferência do Rio, de 1992, e o efeito da adoção dos tratados europeus e das diretivas de política de ambiente europeia.

\section{O ordenamento do território na promoção do desenvolvimento económico e social e da coesão territorial}

A organização económica é uma parte da Constituição que se relaciona estreitamente com os direitos e deveres sociais e, nessa medida, também com o ordenamento do território nas suas dimensões físicas e de desenvolvimento, no quadro do princípio constitucional do "planeamento democrático do desenvolvimento económico e social" (artigo 80., alínea e).

Segundo Marques (1990: 19) é no campo dos direitos fundamentais com incidências económicas e sociais que a Constituição afirma a sua singularidade pela diversidade e extensão de direitos reconhecidos e interesses tutelados. E como referem Miranda e Medeiros (2006: 18) o artigo da definição das incumbências do estado no domínio da organização económica "está intimamente ligado aos direitos e deveres económicos, sociais e culturais, porquanto aí se encontram as concretizações da democracia económica e social aqui assumidas..."

As incumbências atualmente atribuídas ao estado como prioritárias no âmbito económico e social evidenciam bem a ligação com o ordenamento do território, nomeadamente as de: "promover o aumento do bem-estar social e económico e da qualidade de vida das pessoas, em especial das mais desfavorecidas, no quadro de uma estratégia de desenvolvimento sustentável"; "promover a coesão económica e social de todo o território nacional, orientando o desenvolvimento no sentido do crescimento equilibrado de todos os setores e regiões e eliminando progressivamente as diferenças económicas e sociais entre a cidade e o campo e entre o litoral e o interior"; "criar os instrumentos jurídicos e técnicos necessários ao planeamento democrático do desenvolvimento económico e social" e, ainda, as de: "adotar uma política nacional de energia, com preservação dos recursos naturais e do equilíbrio ecológico..."; e "adotar uma política nacional da água, com aproveitamento, planeamento e gestão racional dos recursos hídricos" (artigo 81.o alíneas $a, d, j, m$ e $n$ ).

Mas o quadro constitucional atual difere significativamente do inicial, estabelecido em 1976, uma vez que, na parte da organização económica, a CRP sofreu alterações substanciais, no sentido da eliminação da carga ideológica associada à transição para uma sociedade socialista, da densificação de princípios e da alteração do quadro de planeamento económico e social.

A redação original de 1976 apresentava apenas um fundamento geral da organização económico-social que remetia para o desenvolvimento das relações de produção socialistas e estabelecia um quadro de planeamento em que o 
"Plano" (estruturado nas figuras de longo e médio prazo e anual) orientava, coordenava e disciplinava a organização económica e social do país (artigo 91.

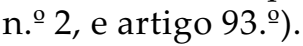

O detalhe dos princípios fundamentais que presidem hoje à organização económica foi introduzido em 1982, tendo sido, nessa data, inscrito o princípio da "planificação democrática da economia, atualizado em 1997 para "planeamento democrático do desenvolvimento económico e social" (artigo 80.ำ alínea e).

Relativamente às incumbências em matéria de organização económico-social, o texto constitucional de 1976 incluiu o núcleo principal das incumbências prioritárias hoje atribuídas ao estado, tendo estas sofrido apenas ajustamentos ou acréscimos relacionados com políticas setoriais que vieram a tornar-se fundamentais no campo da organização e planeamento económico.

Assim, em 1976 já se estabelecia que ao estado incumbe "promover o aumento do bem-estar social e económico e da qualidade de vida das pessoas...", tendo sido, em 1997, acrescentado que esta promoção deve realizar-se "no quadro de uma estratégia de desenvolvimento sustentável". Também as incumbências de "orientar o desenvolvimento económico e social no sentido de um crescimento equilibrado de todos os setores e regiões" $\mathrm{e}$ "eliminar progressivamente as diferenças sociais e económicas entre a cidade e o campo", já estavam presentes no texto de 1976, tendo as mesmas sido agregadas em 1982 sem alteração de conteúdo e, depois, em 2005, aditadas com a menção a diferenças entre "o litoral e o interior" e com a introdução do objetivo de "promoção da coesão económica e social de todo o território nacional".

Em 1997 atualizou-se igualmente a formulação da incumbência de planeamento inscrita em 1976, substituindo-se a menção à criação de "estruturas jurídicas e técnicas" por "instrumentos jurídicos e técnicos" e a referência à "instauração de um sistema de planeamento democrático da economia" por "planeamento democrático do desenvolvimento económico e social".

Em matéria de políticas setoriais, as referências à adoção de uma política nacional de energia e à adoção de uma política nacional da água surgiram, respetivamente, em 1982 e 1997.

De referir que em 1997 os ajustamentos introduzidos trouxeram, tal como sucedeu no capítulo dos direitos e deveres sociais, novos desideratos ao nível das incumbências do estado, designadamente a necessidade de enquadrar a promoção do bem-estar económico e social e da qualidade de vida das pessoas numa "estratégia de desenvolvimento sustentável", remetendo-se para a ideia de harmonização do crescimento económico em respeito pela preservação do ambiente e recursos naturais e pelos efeitos sobre as gerações futuras E reitera-se que foi em 1997 que se inscreveu uma nova tarefa fundamental do estado no âmbito dos princípios fundamentais, no sentido de "promover o desenvolvimento harmonioso de todo o território nacional..." (artigo 9.ำ, alínea $g$ ).

Recorrendo à arrumação temática adotada por Miranda e Medeiros (2006: 18-19), salientamos que as atualizações mencionadas reforçam as tarefas de promoção da igualdade de oportunidades e de promoção do desenvolvimento sustentável, intensificam a ligação entre organização económica, direitos sociais e tarefas 
fundamentais do estado, em torno do desenvolvimento económico e social sustentável de base territorial.

Para além das incumbências, interessa igualmente analisar a evolução dos artigos que estipulam os planos de desenvolvimento económico e social, uma vez que o planeamento é uma componente fundamental organização económica. Canotilho e Moreira (2007: 960) salientam, precisamente, a importância e significado do planeamento no contexto da constituição económica, frisando o seu significado na ideia de orientação económica pelo poder político e na democratização do sistema económico através de instituições democraticamente participadas e frisando que o planeamento no domínio da economia é um dos limites materiais da revisão constitucional (artigo 288., alínea $g$ ).

Sendo a organização económica uma parte da constituição que sofreu profundas alterações, no sentido da eliminação da carga ideológico-programática inicial, em especial em 1989, uma vez de depois da adesão de Portugal à CEE, foi adotado um programa governativo de política económica e social que em vários aspetos se incompatibilizava com o texto constitucional, como referem Canotilho e Moreira (2007: 31), facto é que os objetivos iniciais preconizados para "o Plano" se mantêm-se hoje semelhantes aos do texto originário, e desde sempre associados ao direito ao ambiente e à qualidade de vida, mostrando, neste campo, não só uma grande resiliência como modernidade do texto inicial.

Não obstante a redução significativa da importância do planeamento económico e social, enquanto processo de direção da transformação das estruturas económicas e sociais, e do Plano, enquanto instrumento impositivo de elevada normatividade material, trazida pelas sucessivas revisões constitucionais, como é salientado por Miranda e Medeiros (2006: 131-132), e Canotilho e Moreira (2007: 1032), podemos registar que essas grandes alterações, ligadas à alteração de conceção do modelo de sociedade, não afetaram substancialmente a formulação dos objetivos de desenvolvimento económico e social material a alcançar com os planos, mantendo-se muito do essencial estabelecido em 1976.

Esta resiliência pode ser explicada pelo objetivo do desenvolvimento económico e social em si mesmo e pelas múltiplas dimensões que este objetivo encerra fora da esfera das matérias estritamente económicas. Canotilho e Moreira (2007: 1032) salientam, referindo-se aos planos desenvolvimento económico e social, que “os planos são pressupostos da política económica em geral e orçamental em especial, mas também das demais políticas, em particular das que têm a ver com o ordenamento do território e ambiente".

Atualmente, "os planos de desenvolvimento económico e social têm por objetivo promover o crescimento económico e social, o desenvolvimento harmonioso e integrado dos setores e regiões, a eficiente utilização das forças produtivas, a justa repartição individual e regional do produto nacional, a coordenação da política económica com as políticas: social, educativa e cultural, a defesa do mundo rural, a preservação do equilíbrio ecológico, a defesa do ambiente e a qualidade de vida do povo português" (artigo 90.. ). Com exceção da menção inicial do articulado do artigo 90.. à "promoção do crescimento económico", introduzida em 1989, e das menções ao desenvolvimento "integrado", à política "educativa" e à 
"defesa do mundo rural", introduzidas em 1997, todo o restante conteúdo é originário de 1976.

Independentemente da alteração da natureza e alcance dos planos nacionais, também desde 1976 se prevê que a implementação destes seja descentralizada regional e setorialmente, sem prejuízo da sua coordenação central. Assim, atualmente continua a estabelecer-se que "a execução dos planos nacionais é descentralizada regional e setorialmente (artigo 91.ํ, n.ำ 1), e que "os planos nacionais são elaborados de harmonia com as leis das grandes opções, podendo integrar programas específicos de âmbito territorial e de natureza setorial (artigo 91.o, n... 1), numa redação que, depois de alterações anteriores, foi estabilizada em 1997.

Todavia a inscrição constitucional inicial, segundo a qual, para o efeito, o país seria dividido em "regiões Plano" com base nas potencialidades e nas características geográficas naturais, sociais e humanas do território com vista ao seu equilibrado desenvolvimento e tendo em conta as carências e interesses da população, nos termos da lei (anterior artigo 95.⿳) foi eliminada em $1989 .{ }^{9}$

Foi também em 1989 que se eliminou o Conselho Nacional do Plano, enquanto órgão coordenador da elaboração do Plano, e foi criado o Conselho Económico e Social, como órgão de consulta e concertação no domínio das políticas económica e social e participante na elaboração dos planos de desenvolvimento económico e social.

Para uma melhor compreensão da revisão constitucional de 1989, fora do objetivo de redução da carga ideológico-programática do planeamento do desenvolvimento económico e social e centrada na questão da promoção do desenvolvimento ao nível regional, importa ter em conta os desenvolvimentos infraconstitucionais, legais e administrativos encetados após 1976.

No desenvolvimento dos comandos constitucionais, em 1977 foram encetadas três iniciativas importantes no domínio do planeamento económico e social. Uma delas a aprovação do Sistema e Orgânica de Planeamento e a composição do Conselho Nacional do Plano (Lei n.o 31/77, de 23 de maio). No âmbito desta lei criou-se o Departamento Central e Planeamento (DCP) e uma comissão técnica interministerial de planeamento, a funcionar junto deste, e previu-se a posterior criação e estruturação de departamentos regionais de planeamento em cada região Plano, a funcionar na dependência do ministro do Planeamento.

Ao DCP foi dada a competência técnica de preparar e elaborar o Plano e compatibilizar, nessa sede, os planos setoriais e regionais, incluindo nesta tarefa a de "preparar esquemas de ordenamento do território que, nomeadamente, integrem a preservação do equilíbrio ecológico e a defesa do ambiente, assim como promover a sua concretização através de programas setoriais e regionais" (Lei n.. 31/77, artigo 9.. , n.. 4), uma vez que o Plano deveria assegurar a compatibilização dos vários domínios do planeamento, nas suas componentes económicas, sociais e físicas.

9 Isto não obstante o conceito de região Plano, evoluído para região-planeamento, ter mantido a sua importância no planeamento do desenvolvimento territorial, continuando a ser a base das circunscrições territoriais de atuação das CCDR. 
Aos departamentos regionais de planeamento competiria elaborar estudos de desenvolvimento regional, preparar e acompanhar a execução do respetivo plano regional, e articular os serviços públicos regionais para efeitos de planeamento, porém estes nunca chegaram a existir.

As outras duas iniciativas de 1977 consistiram no lançamento das bases da delimitação das regiões Plano e na preparação de um plano de desenvolvimento para o período de 1977-1980. Destas três iniciativas identificadas por Silva (1984: 32-33) só a aprovação da orgânica de planeamento prosseguiu, embora a sua implementação nunca tivesse chegado a realizar-se por completo. Silva (1984: 29) e Cravinho (1984: 44) referem uma crónica inexistência de planeamento de médio prazo e o segundo sublinha a contradição existente entre a consagração constitucional do planeamento e a interrupção da experiência de planeamento regional que vinha dos anos 60, quando não existia Constituição que o previsse.

Em 1980, tendo em perspetiva a futura adesão à CEE, foi reconhecida a existência de capacidade e experiência de planeamento nas Comissões de Coordenação Regional, através da Resolução n. ${ }^{\text {o }}$ 307/80, de 30 de agosto, ${ }^{10}$ que veio determinar que enquanto não fossem criados os departamentos regionais de planeamento, estes serviços assumiriam a formulação de estudos de base para definição de estratégias de desenvolvimento regional, de apoio à elaboração do plano anual e de médio prazo e de preparação de programas de desenvolvimento regional.

Em 1986, a Lei Orgânica do Ministério do Plano e da Administração do Território (MPAT) e, posteriormente, em 1991, a Lei Quadro do Planeamento (Lei n. ${ }^{-0}$ 43/91, de 27 de julho $)^{11}$ vieram confirmar a atribuição a estas Comissões de funções de planeamento do desenvolvimento económico e social ao nível regional, ${ }^{12}$ até à instituição das regiões administrativas, ${ }^{13}$ funções que estas entidades têm

10 Estas Comissões foram herdeiras dos Comissões Regionais de Planeamento, criadas no final dos anos 60 no âmbito dos Planos de Fomento, estando "incumbidas de exercer, no respetivo âmbito regional, a coordenação e compatibilização das ações de apoio técnico, financeiro e administrativo às autarquias locais e executar, no âmbito dos planos regionais e em colaboração com os serviços competentes, as medidas de interesse para o desenvolvimento da respetiva região, visando a institucionalização de formas de cooperação e diálogo entre as autarquias locais e o poder central" (Decreto-Lei n.. 494/79, de 21 de dezembro: artigo 3...).

11 Aprovada a par com a aprovação da Lei Quadro das Regiões Administrativas (Lei n.ํㅜ 56/91, de 13 de agosto).

12 Por via da Lei Orgânica do MPAT, as CCR passam a ser os "organismos incumbidos de, no respetivo âmbito regional, coordenar e executar as medidas de interesse para o desenvolvimento da respetiva região, promovendo as necessárias ações de apoio técnico e administrativo às autarquias locais nela compreendidas, em ligação com os serviços centrais envolvidos na sua realização", e são identificadas como os órgãos regionais de planeamento para efeitos do previsto no

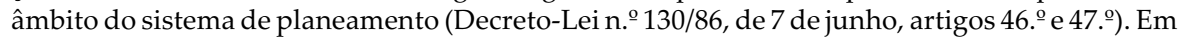
1991, a Lei Quadro do Planeamento, estabeleceu que, "até à instituição das regiões administrativas, incumbe às comissões de coordenação regional preparar e acompanhar a execução dos planos regionais incluídos no Plano" (Lei n. $43 / 91$, de 27 de julho, artigo 12.․․).

13 Segundo Canotilho e Moreira (2007: 1037), "deve distinguir-se, quanto aos planos regionais, entre aqueles que não passam de desenvolvimentos regionais dos planos estaduais e os planos próprios das regiões autónomas (artigo 227. ${ }^{\circ}$ n.. 1 , alínea $p$ ) e das regiões administrativas (arti-

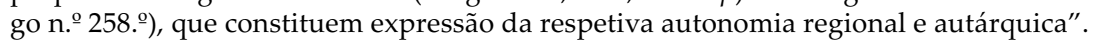


vindo a desempenhar, no quadro das obrigações da política de desenvolvimento regional europeia e no quadro da política de ordenamento do território e dos seus instrumentos de desenvolvimento territorial de âmbito regional.

Esta decisão, estabilizada em 1991 e relançada em 1998, com a configuração do sistema de gestão territorial, promoveu a integração da execução e condução técnica das políticas de ordenamento do território, ambiente e desenvolvimento regional numa mesma entidade regional, criando algumas condições para, na nossa ótica, cumprir melhor os desígnios constitucionais atuais, na ausência de regiões administrativas.

Todavia, independentemente da questão da entidade competente ao nível regional, o sistema de planeamento económico e social nunca chegou a ser efetivado na sua plenitude e alcance, nem na versão original de 1976, o que facilmente se compreende, nem na versão constitucional atual, resumindo-se às grandes opções do plano, anuais e plurianuais, a algum planeamento setorial autónomo e, ao nível regional, por um lado, aos planos e programas de desenvolvimento impostos pela política regional europeia em cada ciclo de fundos comunitários e, por outro lado, aos Planos Regionais de Ordenamento do Território (PROT), no quadro do Programa Nacional da Política de Ordenamento do Território (PNPOT). Todavia, estes dois processos de planeamento e gestão do desenvolvimento territorial regional, que deveriam ser integrados e articular cabalmente o ordenamento do território com o desenvolvimento regional nem sempre se articulam no tempo e na forma e, em determinadas situações, nem no espaço, e escasseiam na objetivação do investimento público em articulação com as grandes opções e o orçamento.

Salienta-se a propósito da articulação de instrumentos a nota de Canotilho e Moreira (2007: 1033), que referem que o planeamento constitui o principal instrumento de orientação pública da economia, quer por via da programação do investimento público, quer pela articulação dos vários instrumentos de fomento e de incentivo, salientando a função dos planos de coordenar e conferir unidade aos instrumentos públicos de regulação económica.

A elaboração da LBPOTU aprovada em $1998^{14}$ teve esse objetivo de integração, podendo ler-se na definição do seu âmbito (artigo 1. ${ }^{\circ}$, n. .0 da Lei n.. 48/98, de 22 de setembro) que "a política de ordenamento do território e de urbanismo define e integra as ações promovidas pela administração pública, visando assegurar uma adequada organização e utilização do território nacional, na perspetiva da sua valorização, designadamente no espaço europeu, tendo como finalidade o desenvolvimento económico, social e cultural integrado, harmonioso e sustentável do País, das diferentes regiões e aglomerados urbanos".

Salienta-se, a este propósito, o registo efetuado pelo ex-ministro João Cravinho, responsável pela elaboração da LBPOTU, no evento de comemoração dos dez anos da Lei, em 2010: "A Constituição da República considera tarefa fundamental do estado assegurar um correto ordenamento do território. À obrigação constitucional

14 A Lei de Bases foi revista em 2014, encontrando-se atualmente em vigor a nova Lei da Política

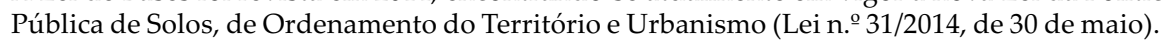


tem correspondido um claro défice de intervenção do estado. Importava assim criar um corpo legislativo e doutrinário que constituísse referência para a coordenação das políticas de base territorial e superasse o caráter residual habitualmente atribuído pelas políticas de desenvolvimento económico e social às questões territoriais e ao desenvolvimento urbano." (Cravinho, 2010: 17). Refere ainda neste registo que a ambição da LBPOTU foi a de "construir um sistema nacional capaz de colocar as políticas territoriais no campo próprio da interação com as políticas de desenvolvimento económico e social e definir um sistema de instrumentos diferenciados, cada um do seu modo, mas em profunda articulação" (Cravinho, 2010: 18).

Estes desígnios não se cumpriram cabalmente. A política de ordenamento do território tem tido dificuldades em congregar de forma eficaz e eficiente a tríade de políticas que constituem o seu núcleo: o ordenamento do território, o ambiente e o desenvolvimento regional, entre outras razões, por falta de operacionalização do sistema de planeamento (faltam planos, falta dinâmica de planos e faltam processos de planeamento) e por falta de aplicação do princípio da interação coordenada dos planos, um dos princípios basilares do sistema que tem servido, sobretudo, para conformar prevalências entre planos e pouco para gerir, com efetividade, os vários processos e conteúdos dos planos e a aplicação concertada destes no tempo e no espaço.

Segundo Ferrão (2011: 25), “o ordenamento do território no contexto das políticas públicas, corresponde, em Portugal, a uma política duplamente 'fraca'; fraca em relação à sua missão, dada a desproporção que se verifica entre a ambição dos objetivos visados e as condições efetivas para os atingir; e fraca em relação aos efeitos indesejados decorrentes de outras políticas, dada a sua vulnerabilidade em relação a impactes negativos à luz dos objetivos e princípios de ordenamento do território". Para esta situação contribuem "uma cultura cívica de ordenamento do território incipiente; uma cultura político-administrativa pouco favorável à coordenação intersetorial de base territorial" (Ferrão, 2011:131), entre outros aspetos.

Por sua vez, a política de desenvolvimento regional foi restringindo o seu foco à política regional europeia e aos sucessivos períodos de programação de fundos estruturais, pelo que atualmente, como salienta Figueiredo (2010: 65), "não existe um corpo estabilizado de políticas públicas com essas características que possam considerar-se autónomas face aos diferentes instrumentos de política com cofinanciamento comunitário", situação, segundo o autor, explicada por razões de natureza institucional, ligadas à orgânica de planeamento e a elementos que marcam uma dependência de percurso.

A política de ambiente tem prosseguido a sua afirmação sob proteção das imposições e diretivas comunitárias, mas encontra fortes obstáculos à concretização dos desígnios do desenvolvimento sustentável, por falhas de integração do ordenamento do território e do desenvolvimento económico e social. 


\section{O ordenamento do território como contribuinte da concretização dos princípios de subsidiariedade, autonomia, descentralização e participação}

O princípio democrático do estado assenta em três componentes formais de organização da democracia política: (i) a soberania ou vontade popular que concede o poder político através de sufrágio universal, igual, direto e secreto; (ii) a participação democrática dos cidadãos na resolução dos problemas nacionais, sob variadas formas e instâncias; (iii) a descentralização, por via da autonomia local e regional (Canotilho e Moreira, 2007: 206).

Da conjugação destas três componentes resultam, na nossa perspetiva, duas ideias principais que perpassam o texto constitucional e conformam princípios fundamentais: a participação e envolvimento dos cidadãos na definição e na aplicação das políticas públicas (que visam a resolução dos problemas nacionais), como princípio básico; e a territorialização das políticas públicas, através de várias formas de partilha de poderes, de legitimação e de definição de espaços de racionalidade da decisão pública, enquanto instrumento essencial da consagração daquele princípio.

Em complemento, referem os autores acima citados que o estado de direito democrático visa a realização da democracia económica, social e cultural, traduzida nas responsabilidades públicas de promoção do desenvolvimento económico, social e cultural, de satisfação de níveis básicos de prestações para todos e de correção de desigualdades sociais, entre outras dimensões, e, em simultâneo, o aprofundamento da democracia participativa, na medida em que estas duas dimensões são fundamentais para a democracia plena (Canotilho e Moreira, 2007: 209-211).

Como foi evidenciado nos pontos anteriores, a política de ordenamento do território, em particular através do seu sistema de planeamento, tem um papel importante na concretização dos princípios da subsidiariedade, da autonomia, da descentralização e da participação, previstos na CRP e na ordem jurídico-administrativa infraconstitucional desenvolvida ao abrigo dos princípios constitucionais e das reservas de competência legislativa.

Sem querer repetir o que já foi explanado, passamos a sistematizar o contributo do ordenamento do território para a concretização dos princípios de subsidiariedade, autonomia, descentralização e participação.

Em primeiro lugar, o ordenamento do território contribui para estes princípios através da concretização das funções de planeamento, gestão e prestação de serviços que enformam as incumbências do estado, no seu sentido amplo, associadas à tarefa de "assegurar um correto ordenamento do território". Essas tarefas inscrevem-se:

- quer no quadro dos princípios fundamentais - no âmbito do artigo 9. ${ }^{\circ}$, abarcando: a proteção e valorização do património cultural, a defesa da natureza e do ambiente e a preservação dos recursos naturais; a promoção do bem-estar e da qualidade de vida e a efetivação dos direitos económicos, sociais, culturais e ambientais; a promoção do desenvolvimento territorial harmonioso; 
- quer, também, no quadro das incumbências prioritárias do estado no âmbito económico e social - no âmbito do artigo 81. ․, nomeadamente no que se refere a: promoção do aumento do bem-estar social e económico e da qualidade de vida das pessoas no quadro de uma estratégia de desenvolvimento sustentável; promoção da coesão económica e social de todo o território nacional, orientando o desenvolvimento no sentido do crescimento equilibrado de todos os setores e regiões e eliminando progressivamente as diferenças económicas e sociais entre a cidade e o campo e entre o litoral e o interior;

- quer, ainda, no âmbito do artigo 93.․ - no que se refere à promoção de ordenamento agrário e desenvolvimento florestal de acordo com condicionalismos ecológicos e sociais.

Em segundo lugar, o ordenamento do território contribui para os referidos princípios através da organização e condução do processo de planeamento. A própria Constituição impõe algumas tarefas e incumbências de índole processual e procedimental, como é caso da tarefa de assegurar e incentivar a participação democrática dos cidadãos na resolução dos problemas nacionais (artigo 9.o, alínea c), traduzida especificamente na garantia da participação dos interessados na elaboração dos instrumentos de planeamento urbanístico (artigo 65.ำ n.ำ 5 ) e na obrigação de envolver os cidadãos nas incumbências de assegurar o direito ao ambiente (artigo 66. ․ㅡ. n. 2 ), e como é o caso do princípio fundamental de planeamento democrático do desenvolvimento económico e social (artigo 80.ํ), traduzido na obrigação de execução descentralizada dos planos nacionais (artigo 91. ${ }^{\circ}$, n.․ㅜ 3) e na composição do Conselho Económico e Social (artigo 92..$^{\circ}$, n.ํำ 2).

Em terceiro lugar, o contributo do ordenamento do território expressa-se na materialização e partilha de poderes e na formatação da descentralização e desconcentração de competências entre o estado, as regiões autónomas e as autarquias locais e entre os vários níveis e âmbitos da atuação da administração pública. Salienta-se que em vários domínios, nomeadamente ao nível dos direitos sociais e do desenvolvimento económico e social, a Constituição institui um sistema de competências concorrentes entre o estado, as regiões autónomas e as autarquias locais, cuja delimitação foi formatada na LBPOTU e no Regime Jurídico dos Instrumentos de Gestão Territorial.

Para este efeito a LBPOTU previu um sistema de planeamento que organiza os âmbitos territoriais de atuação ao nível nacional, regional e local e define as esferas de competência dos órgãos de cada nível, contando com a existência de regiões administrativas no nível intermédio de organização administrativa, entre os municípios e o estado, estabelecendo ainda as bases da relação entre o planeamento biofísico de índole reguladora e o planeamento do desenvolvimento territorial, de caráter estratégico, programático e orientador.

Salientam Miranda e Medeiros (2006: 1336) que o ordenamento do território e o urbanismo constituem um domínio claramente aberto à intervenção concorrente do estado, das regiões autónomas e das autarquias locais, e que a conjugação do artigo 65. ., n.. 2, alínea $a$, e n. ${ }^{\text {os }} 4$ e 5, em coerência com a elevação do correto ordenamento do território como tarefa fundamental do estado (artigo 9.‥ alínea $c$ ), bem 


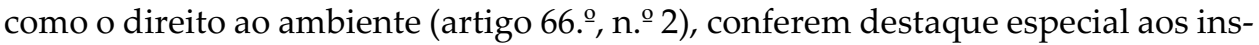
trumentos de planeamento, no espaço que lhes é balizado por lei.

Efetivamente os planos são instrumentos conformadores da vida social e de programação infraestrutural; projetam a realização do interesse público no futuro; têm um conteúdo orientador do desenvolvimento territorial sustentável (económico, social, ambiental e cultural); têm uma aplicabilidade dilatada no tempo, ao longo do horizonte temporal da sua vigência; apresentam uma formatação dirigida a relações duradoras e não determinadas com cidadãos; são conformadores dos próprios interesses públicos, no quadro legal habilitantes. Neste âmbito da conformação da vida social abre-se amplo espaço para a efetivação dos princípios da subsidiariedade, autonomia, descentralização e participação.

A inscrição do ordenamento do território como tarefa fundamental, lida no contexto das demais tarefas e incumbências do estado, realça a ligação entre os princípios políticos fundamentais, associados ao estado social, ao estado de direito ambiental e ao estado de direito democrático e reforça a efetivação da democracia económica, social e cultural através dos direitos à habitação e urbanismo e ao ambiente e qualidade de vida, dos objetivos de desenvolvimento económico e social harmonioso, equilibrado e sustentável e dos desideratos da subsidiariedade e do aprofundamento da democracia participativa.

Apesar de já estarem presentes no texto originário de 1976 as sucessivas revisões constitucionais de 1982, 1989 e 1997 aprofundaram as referências à democracia participativa com consequências na definição do sistema de gestão territorial, afirmando o direito da participação através da audiência prévia na elaboração de planos e da consulta pública das propostas dos planos, e de outras formas de estímulo da cidadania territorial, indispensáveis à prossecução das tarefas do estado referentes ao correto ordenamento do território e ao desenvolvimento económico e social.

A propósito do n. 5 do artigo 65. ${ }^{\circ}$, Canotilho e Moreira (2007: 839-840) salientam que esta é uma concretização, em sede de ordenamento e urbanismo, do direito de participação dos interessados nas tarefas e estruturas da administração, previsto no artigo 267.․ , n. ${ }^{\circ}$ 1. Para os autores: "A Constituição visou alicerçar a democracia participativa no âmbito do planeamento territorial procurando estimular uma cidadania territorial indispensável à prossecução das tarefas do estado referentes ao correto ordenamento do território e desenvolvimento harmonioso."

A democracia participativa concretiza-se por via da institucionalização de processos e procedimentos, formais e informais, de participação e envolvimento dos cidadãos e de grupos de interesse na formulação, execução e avaliação das políticas e dos instrumentos de planeamento e gestão, estando o seu aprofundamento, naturalmente, ligado ao bom funcionamento do sistema de planeamento.

No que se reporta à territorialização, os princípios da subsidiariedade, da autonomia regional e do poder local, conjugados com os princípios instrumentais da descentralização e da desconcentração, estão na origem de vários processos de reforma da organização territorial da administração do estado e de associativismo municipal. Todavia não foi, até à data, completado o quadro organizativo previsto na Constituição para o poder local, com a criação de regiões administrativas. 
A Constituição de 1976 consagrou a autonomia do poder local, dentro da unicidade do estado, e estabeleceu a criação de autarquias locais, desde logo os municípios e freguesias e, a seu tempo, as regiões administrativas e outras formas de organização territorial autárquica, passíveis de se constituir nas grandes áreas urbanas e nas ilhas (artigo 236. ${ }^{\circ}$ ).

Embora a Constituição preveja, desde 1976, a criação de regiões administrativas, e apesar de várias iniciativas legislativas dirigidas nesse sentido - nomeadamente, em 1982, a publicação dos princípios e opções da regionalização, em 1991, a Lei Quadro das Regiões Administrativas e, em 1998, a lei da criação das oito regiões administrativas, objeto de referendo - não foi até agora concretizada a criação efetiva das regiões, tendo a questão ficado arredada do debate político principal a partir de 1998, com o resultado negativo do referido referendo.

Como referem Canotilho e Moreira (2007: 1033, 1037), a Constituição prevê um sistema de planeamento multinível, que inclui planos nacionais da responsabilidade do estado, com declinações setoriais e regionais, mas também planos regionais das entidades territoriais de âmbito regional, quer as regiões autónomas, com competências de aprovar o seu plano de desenvolvimento económico e social e participar no nacional, quer as regiões administrativas, com competências de elaboração de planos regionais e participação na elaboração dos nacionais.

Na ausência das regiões administrativas, tem cabido às regiões-planeamento e às respetivas $C C D R$, enquanto órgãos da administração periférica do estado competentes, a execução e condução das políticas públicas de ordenamento do território, ambiente e desenvolvimento regional, o apoio às autarquias e a programação e governação de fundos estruturais e de investimento, prosseguindo os princípios constitucionais e as diretrizes do quadro legal de desenvolvimento infraconstitucional, no âmbito regional.

\section{Conclusões}

O ordenamento do território foi inscrito no texto original da Constituição de 1976, como uma obrigação do estado transversal e enquadradora da efetivação dos direitos à habitação e ao ambiente e qualidade de vida e como um instrumento necessário ao planeamento de base económica.

Em 1989 reforçou o seu estatuto constitucional, ao ser assumido explicitamente como uma tarefa fundamental e autónoma do estado, e ganhou amplo espaço no domínio do planeamento do desenvolvimento económico e social, a partir da eliminação do planeamento económico dirigista.

O estatuto constitucional que reconhecemos ao ordenamento do território tem tradução na ordem jurídica infraconstitucional mas não tem, todavia, correspondentes reflexos na prática, nem na importância social que lhe é, frequentemente, atribuída, nem no seu efetivo desempenho no quadro das demais políticas públicas.

Para a concretização da ambição que a Constituição impõe falta prática de planeamento de base territorial no seu ciclo processual completo, falta cumprir 
melhor o planeamento do desenvolvimento económico e social, numa lógica do desenvolvimento territorial alicerçado no ordenamento do território e no desenvolvimento regional, e falta também, ou sobretudo, organização político-administrativa estável e consistente, capaz de responder aos encargos e obrigações constitucionais.

Na presente legislatura o XXI Governo Constitucional inscreveu no seu programa uma medida de reforma da administração territorial ao nível regional da qual se espera um contributo significativo para o aprofundamento dos princípios constitucionais, no sentido do reforço da integração efetiva das políticas de ordenamento do território, ambiente e desenvolvimento regional e da criação de uma nova racionalidade de integração das dimensões territoriais das políticas setoriais.

Dadas as características da organização político-administrativa regional no continente, importa na sede desta reforma debater com profundidade e sedimentar socialmente um modelo de organização, funcionamento e delimitação de competências das CCDR que viabilize e facilite a realização do que realmente interessa realizar no âmbito regional, tendo em vista a promoção da organização territorial e do desenvolvimento económico e social harmonioso, integrado e sustentável, como decorre da CRP.

\section{Referências bibliográficas}

Ad Urbem (2010), Os Dez Anos da Lei de Bases da Política de Ordenamento do Território e Urbanismo, Lisboa, Direção-Geral do Ordenamento do Território e

Desenvolvimento Urbano e Fundação para a Ciência e a Tecnologia.

Amaral, Diogo Freitas do (2006), Curso de Direito Administrativo, Coimbra, Edições Almedina

Campos, Vítor, e João Ferrão (2015), “O ordenamento do território em Portugal: uma perspetiva genealógica", ICS Working Papers, 1.

Canotilho, J. J. Gomes, e Vital Moreira (2007), Constituição da República Portuguesa Anotada, vol. I, Coimbra, Coimbra Editora.

Carmo, Fernanda do (2013), Governança Territorial e Administração Periférica. Uma (Re)Visão a Partir dos Planos Regionais de Ordenamento do Território, Lisboa, ISCTE Instituto Universitário de Lisboa, dissertação de mestrado em Administração Pública, disponível em: http://biblioteca.versila.com/3338921 (última consulta em setembro de 2016).

Cravinho, João (1984), “Portugal: um país em crise entre o 'desplaneamento' e as políticas de estabilização", em AA.VV., O Planeamento Económico em Portugal. Lições da Experiência, Lisboa, Sá da Costa.

Cravinho, João (2010), “Génese da Lei de Bases da Política de Ordenamento do Território e Urbanismo", em Ad Urbem, Os Dez Anos da Lei de Bases da Política de Ordenamento do Território e Urbanismo, Lisboa, Direção-Geral do Ordenamento do Território e Desenvolvimento Urbano e Fundação para a Ciência e a Tecnologia.

DGOT - Direção-Geral do Ordenamento do Território (1988), Carta Europeia do Ordenamento do Território, Lisboa, SGMPAT.

Fadigas, Leonel (2015), Urbanismo e Território. As Políticas Públicas, Lisboa, Sílabo. 
Ferrão, João (2010), “Uma visão política da evolução da política de ordenamento do território", em Juventude Socialista (org.), Socialismo no Séc. XXI, Lisboa, Esfera do Caos, pp. 62-79.

Ferrão, João (2011), O Ordenamento do Território como Política Pública, Lisboa, Fundação Calouste Gulbenkian.

Figueiredo, António M. (2010), A Territorialização de Políticas Públicas em Portugal, Lisboa, Instituto Financeiro para o Desenvolvimento Regional.

Garcia, Maria da Glória (2010), “Constituição e ordenamento do território”, em Ad Urbem, Os Dez Anos da Lei de Bases da Política de Ordenamento do Território e de Urbanismo, Lisboa, Direção-Geral do Ordenamento do Território e Desenvolvimento Urbano e Fundação para a Ciência e a Tecnologia.

Marques, Maria Manuel (1990), A Constituição Económica Portuguesa depois da Revisão Constitucional de 1989, Coimbra, Oficina do CES.

Miranda, Jorge, e Rui Medeiros (2006), Constituição Portuguesa - Anotada, tomo II, Coimbra, Coimbra Editora.

Pitschieller, João, e Sofia Abreu (1989), “Enquadramento geral das operações urbanísticas", em Diogo Freitas do Amaral (coord.), Direito do Urbanismo, Oeiras, Instituto Nacional de Administração.

Silva, Manuela (1984), “O planeamento em Portugal: lições da experiência e perspectivas de futuro", em AA.VV., O Planeamento Económico em Portugal. Lições da Experiência, Lisboa, Sá da Costa, pp. 13-41.

Sousa, Marcelo Rebelo de, e André S. de Matos (2008), Direito Administrativo Geral, Lisboa, Publicações Dom Quixote.

Fernanda do Carmo. Doutoranda em Políticas Públicas, Instituto Universitário de

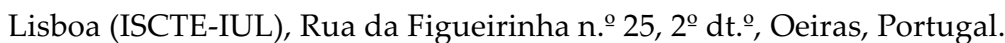

E-mail: fmr.carmo@gmail.com 